\title{
ELIMINAÇÃO DE EPIMASTIGOTAS E TRIPOMASTIGOTAS ESTIMADA ATRAVÉS DA LEITURA DO XENODIAGNÓSTICO, PELO MÉTODO DAS DEJEÇÕES ESPONTÂNEAS
}

\author{
Heloisa Helena Garcia da Silva", Adelair Helena dos Santos" , Eliana Isac \& \\ Ionizete Garcia da Silva $\cdots$
}

\section{RESUMO}

A partir do xenodiagnóstico aplicado em 30 pacientes chagásicos crônicos, com parasitemia detectável, avaliou-se a quantidade de epimastigotas e tripomastigotas, eliminados através das fezes e da urina dos triatomíneos.

Nas fezes, a quantidade de epimastigotas foi, significativamente maior do que tripomastigotas, e na urina houve uma inversão: a quantidade de tripomastigotas foi significativamente maior do que epimastigotas, pelo teste $t$, ao nível de $1 \%$.

Os experimentos foram realizados numa câmara biológica à temperatura de $28 \pm 1^{\circ} \mathrm{C}$. umidade relativa de $70 \pm 5 \%$, fotoperíodo de 12 horas.

UNITERMOS: Xenodiagnóstico, Doença de Chagas, Trypanosoma cruzi, formas evolutivas.

\section{INTRODUÇÃO}

Na pesquisa básica em doença de Chagas, utiliza-se, de rotina, inóculo de Trypanosoma cruzi em animais de laboratório. A infectividade do tripanossoma é alta

- Farmacêutica de Dept. ${ }^{\circ}$ de Parasitologia - IPTSP/UFG

*. Aluna do Curso de Mestrado em Patologia Tropical - IPTSP/UFG

-.. Profs. do Dept. ${ }^{\circ}$ de Parasitologia - IPTSP/UFG

Apoio financeiro: SENESU/PRPPG-UFG, FUNAP-UFG

- Recebido para publicaçāo em 05/04/94 
SILVA,H.H.G.; SANTOS,A.H.; ISAC,E. \& SILVA.I.G. Eliminação de epimastigotas e tripomastigotas estimada através de leitura do xenodiagnóstico, pelo método das dejeçōes espontâneas. Rev.Pat. Trop.,23(1):101-106,jan./jun.1994.

quando o inóculo é feito de sangue de um animal infectado em outro suscetível, porém quando se inocula fezes de triatomíneos em animais de laboratório, a infectividade é baixa. Neste trabalho, estudou-se a quantidade de formas tripomastigotas e epimastigotas eliminadas nas fezes e na urina, com a finalidade de otimizar a preparação e infectividade de inóculos, realizados com fezes de triatomíneos infectados pelo T.cruzi, para animais de laboratório.

\section{MATERIAL E MÉTODOS}

O xenodiagnóstico foi aplicado em 30 pacientes chagásicos, que apresentavam parasitemia detectável, de um total de 206 estudados, na fase crônica e não tratados, do Hospital das Clínicas da Universidade Federal de Goiás, dos quais eram conhecidos os exames clínico e sorológico (imunofluorescência indireta c hemaglutinação indireta) com soros reatógenos.

Em todos os pacientes, o xenodiagnóstico foi realizado com ninfas de 4 . $^{\circ}$ e $5 .^{\circ}$ estádios de Triatoma infestans criadas numa câmara biológica à temperatura de $25 \pm 1^{\circ} \mathrm{C}$, umidade relativa de $70 \pm 5 \%$ e fotoperíodo de 12 horas $^{2}$. Imediatamente após a ecdise para o $4 .^{\circ}$ e $5 .^{\circ}$ estádios, as ninfas eram separadas em frascos de polietileno, transparentes, cilíndricos medindo $3 \times 5 \mathrm{~cm}$, com tampas perfuradas ao centro e a estas coladas uma tela fina de náilon, com cerca de 250 malhas por $\mathrm{cm}^{2}$, o fundo forrado com papel filtro e, perpendicular a este e à tampa, um pedaço de cartolina como substrato para os triatomíneos se alimentarem. Nestes, permanecem em jejum, por 25 e 30 dias, para $4^{\circ}$ e $5^{\circ}$ estádios, respectivamente. Após este período, aplicava-se o xenodiagnóstico e, em seguida, os triatomíneos eram acondicionados numa câmara (CDG-247 da FANEN) à temperatura de $28 \pm 1^{\circ} \mathrm{C}$, umidade relativa de $70 \pm \%$ e fotoperíodo de 12 horas.

As leituras foram realizadas após 30 dias, pelo método das dejeções espontâneas ${ }^{3,5}$. Basicamente, esta técnica consiste em alimentar o triatomíneo até a repleção total ${ }^{6}$, que é condição fundamental para o inseto eliminar as dejeçōes. Para isto, camundongos foram imobilizados em tela de náilon como mostra a Fig.1, com a cabeça recurvada para o ventre, para que o animal não furasse a tela. Em volta do corpo do camundongo a tela foi grampeada de forma a nāo permitir nenhum movimento e, posteriormente, era afixado aos tubos com os triatomíneos ${ }^{4}$. Após 3 a 4 minutos os triatomíneos eliminam as fezes, e, de 10 a 40 minutos eliminam a urina. As primeiras gotas do material fecal são densas e escuras, exceto após a ecdise, quando são amareladas e se cristalizam rapidamente. As gotas subseqüentes,
SILVA,H.H.G.; SANTOS,A.H.; ISAC,E. \& SILVA,I.G. Eliminaçāo de epimastigotas e tripomastigotas estimada através de leitura do xenodiagnóstico, pelo método das dejeçōes espontâneas. Rev.Pat.Trop.,23(1):101-106,jan./jun.1994.

vão clareando até tornarem-se hialinas, neste caso considerou-se como a urina. Com o auxílio de micropipetador e com a tampa aberta apenas o necessário para introduzilo no frasco, colhia-se fezes ou urina, examinava-se entre lâmina e lamínula ao microscópio de inversão com médio aumento (400x) e contava-se o número de tripanossomas ${ }^{1}$.

As formas epimastigotas e tripomastigotas foram diferenciadas pela morfologia e pela mobilidade que se apresenta chicoteante, lenta e com movimento irregular para epimastigotas e, serpenteante, rápida e direcional, para tripomastigotas.

\section{RESULTADOS}

Os resultados são apresentados na Tabela 1. A quantidade de formas epimastigotas foi significativamente maior do que as tripomastigotas, nas fezes e, na urina houve uma inversāo, a quantidade de tripomastigotas foi significativamente maior do que epimastigotas. Verificou-se, também, que não houve resultado negativo para epimastigotas nas fezes e nem tripomastigotas na urina em nenhum dos pacientes estudados.

\section{DISCUSSĀO}

A partir deste trabalho e com o uso da técnica das dejeçōes espontâneas, tornar-se-á mais fácil a preparação de inóculos com a urina e, por conseguinte, maior sucesso na infecção de camundongos?

A técnica das dejeçōes espontâneas permite realizar a leitura do xenodiagnostico quantas vezes for conveniente, devido ao fato de se alimentar o triatomíneo para se obterem as dejeções sem causar-lhe nenhum tipo de traumatismo. É caracteŕística dessa técnica a utilização do material fecal sem diluí-lo em solução salina, como é feito com o método da compressão abdominal e neste trabalho, evidenciou-se uma predominância de epimastigotas sobre as tripomastigotas; examinar separadamente fezes e urina e/ou um "pool" delas. O exame separado da urina ficou caracterizado pela predominância de tripomastigotas em material hialino, praticamente livre de contaminação de fungos e de bactérias, possibilitando assim, uma melhor infectividade de animais de laboratório e/ou clonagem de cepas. Além disso, essa técnica permite estudar a relação parasito-hospedeiro e a curva parasitêmica do vetor infectado, durante todo o seu desenvolvimento ninfal e sua longevidade. 
SILVA,H.H.G.; SANTOS,A.H.; ISAC,E. \& SILVA,I.G. Eliminaçāo de epimastigotas e tripomastigotas estimada através de leitura do xenodiagnóstico, pelo método das dejeçōes espontâneas. Rev.Pat.Trop.,23(1):101-106,jan.jjun.1994.

Tabela 1 - Quantidade de formas epimastigotas e tripomastigotas eliminadas pelo Triatoma infestans e estimada por lâmina, através da leitura do xenodiagnóstico.

PACIENTES

FEZES

URINA

$\overline{\text { Epimastigota }}$ Tripomastigota

$\overline{\text { Epimastigota }}$ Tripomastigota

\begin{tabular}{|c|c|c|c|c|}
\hline 01 & 107 & 76 & 72 & 162 \\
\hline 02 & 14 & 10 & 26 & 50 \\
\hline 03 & 03 & 00 & 00 & 61 \\
\hline 04 & 210 & 12 & 00 & 15 \\
\hline 05 & 05 & 05 & 02 & 05 \\
\hline 06 & 25 & 100 & 09 & 90 \\
\hline 07 & 01 & 09 & 250 & 350 \\
\hline 08 & 01 & 05 & 00 & 02 \\
\hline 09 & 03 & 00 & 00 & 04 \\
\hline 10 & 04 & 02 & 02 & 03 \\
\hline 11 & 02 & 00 & 02 & 08 \\
\hline 12 & 05 & 00 & 00 & 20 \\
\hline 13 & 10 & 01 & 10 & 10 \\
\hline 14 & 02 & 48 & 81 & 496 \\
\hline 15 & 15 & 02 & 52 & 101 \\
\hline 16 & 12 & 00 & 00 & 172 \\
\hline 17 & 10 & 39 & 15 & 50 \\
\hline 18 & 122 & 12 & 441 & 32 \\
\hline 19 & 02 & 03 & 21 & 101 \\
\hline 20 & 106 & 09 & 00 & 61 \\
\hline 21 & 72 & 00 & 00 & 153 \\
\hline 22 & 80 & 61 & 12 & 04 \\
\hline 23 & 30 & 07 & 17 & 183 \\
\hline 24 & 04 & 00 & 00 & 55 \\
\hline 25 & 02 & 00 & 03 & 03 \\
\hline 26 & 15 & 03 & 05 & 60 \\
\hline 27 & 03 & 00 & 00 & 26 \\
\hline 28 & 84 & 00 & 00 & 05 \\
\hline 29 & 50 & 00 & 00 & 19 \\
\hline 30 & 138 & 02 & 00 & 15 \\
\hline $\begin{array}{l}\text { MÉDIA } \\
\text { ERRO }\end{array}$ & 37,9 & 13,5 & 34,3 & 100.5 \\
\hline PADRÃO & $\pm 9,7$ & $\pm 4,6$ & \pm 16.3 & \pm 29.6 \\
\hline
\end{tabular}

SILVA,H.H.G.; SANTOS,A.H.; ISAC,E. \& SILVA,I.G. Eliminaçăo de epimastigotas e tripomastigotas estimada através de leitura do xenodiagnóstico, pelo método das dejeçōes espontâneas. Rev.Pat. Trop.,23(1):101-106,jan./jun.1994.

A inoculação da urina ao invés de fezes, apresenta as seguintes vantagens: ter maior número de tripomastigotas, inóculo com pouca contaminação e maior infectividade.

\section{SUMMARY}

Epimastigote and tripomastigote elimination by xenodiagnosis reading by spontaneous dejection method

Thirty patients on the chronic phase of Chagas' disease were submited to xenodiagnosis, in order to evaluate the quantity of evolutive forms (epimastigote and tripomastigote).

In faeces, the quantity of epimastigotes was significantly higher than with tripomastigotes. In urine, the number of tripomastigotes was significantly higher than with epimastigote by spontaneous dejection method $(t$ test, $\mathrm{p}<0,01)$.

The experiments were performed at $28 \pm 1^{\circ} \mathrm{C}, 70 \pm 5 \%$ of relative humidity and fhotoperiod of $12 \mathrm{~h}$.

KEYWORDS: Xenodiagnosis, Chagas' disease, Trypanosoma cruzi, evolutive forms.

\section{REFERÊNCIAS BIBLIOGRÁFICAS}

01. BRENER,Z. Contribuição ao estudo da terapêutica experimental da doença de Chagas. Tese de Livre Docência, Faculdade de Odontologia e Farmácia de Minas Gerais, Belo Horizonte, 1961.

02. SILVA,I.G. Influência da temperatura na biologia de triatomíneos.I.Triatoma rubrovaria (Blanchard,1843) (Hemiptera, Reduviidae). Rev.Goiana Med., 31:1-37, 1985.

03. SILVA,I.G. Nova técnica para a leitura do xenodiagnóstico.Rev.Goiana Med., 36:35-39, 1990.

04. SILVA,I.G. \& FERREIRA,I.R. Influência da fonte sanguínea na multiplicação da cepa $Y$ de Trypanosoma cruzi em Triatoma infestans (Klug,1834) e Rhodnius neglectus Lent,1954. Rev. Goiana Med., 36:41-48, 1990. 
SILVA,H.H.G.; SANTOS,A.H.; ISAC,E. \& SILVA,I.G. Eliminaçāo de epimastigotas e tripomastigotas estimada através de leitura do xenodiagnóstico, pelo método das dejeçōes espontâneas. Rev.Pat.Trop.,23(1):101-106,jan./jun.1994.

05. SILVA,I.G.; OSTERMAYER,A.L. \& SILVA,H.H.G. Importância do método de obtençāo das dejeçōes dos triatomíneos na avaliação da suscetibilidade triatomínica ao Trypanosoma cruzi.Rev.Soc.Bras. Med.Trop., 26: 19-24, 1993.

06. SILVA,I.G \& SILVA,H.H.G. Estudo comparado do desenvolvimento de triatomíneos a duas temperaturas. Mem.Inst.Oswaldo Cruz,84:499-500, 1989.

07. SILVA,I.G \& SILVA,H.H.G. Suscetibilidade de 11 espécimes de 7 triatomíneos (Hemiptera, Reduviidae) à cepa $Y$ de Trypanosoma cruzi (Kinetoplastida, Tripanossomatidae).Rev.Bras.Ent., 37:459-463, 1993. 